Communication

\title{
Exposure Assessment Methods in Studies on Waste Management and Health Effects: An Overview
}

\author{
Andrea Spinazzè *, Francesca Borghi, Sabrina Rovelli and Domenico Maria Cavallo \\ Dipartimento di Scienza e Alta Tecnologia, Università degli Studi dell'Insubria, Via Valleggio 11, Como 22100, \\ Italy; f.borghi2@uninsubria.it (F.B.); sabrina.rovelli@uninsubria.it (S.R.); \\ domenico.cavallo@uninsubria.it (D.M.C.) \\ * Correspondence: andrea.spinazze@uninsubria.it; Tel.: +39-031-238-6629
}

Academic Editor: Yu-Pin Lin

Received: 30 January 2017; Accepted: 18 February 2017; Published: 21 February 2017

\begin{abstract}
Concerns and uncertainties persist about potential environmental and health effects associated with exposure to emissions from widely adopted waste management facilities: despite a limited amount of evidence having been found for some exposure-effect associations, most of the available studies were characterized by limitations related to poor exposure assessment, which could introduce biases and weaknesses in the interpretation of results. This communication provides a brief overview of the exposure assessment methods used in studies on waste management and health effects: problems, key issues, priorities and challenges are briefly presented and discussed. The main conclusions refer to the need of newly developed and harmonized exposure assessment strategies and techniques, which represent an essential step in the study of waste-disposal facilities' health impacts.
\end{abstract}

Keywords: exposure assessment; waste; waste management; waste disposal; waste incinerator; landfill; health impact; health effect; environmental exposure; population health

\section{Introduction}

Waste management (i.e., the generation, collection, processing, transport, and disposal of solid waste) is important for both environmental and public health. Concerns and uncertainties persist about potential environmental and health effects associated with exposure to emissions from widely adopted waste management facilities (i.e., waste disposal—landfills and energy recovery-incinerators) [1]. In this regard, several studies and a number of reviews are available, leading to the conclusion that (i) concerns persists over the health effects of different waste management options, despite the lack of univocal evidence on the health implications of waste-related environmental exposures [2,3]; and that (ii) emissions from landfills and incinerators could be associated with some health outcomes [2,4-7]. It also should be considered that a distinction should be made between the impact of waste management sites for household solid wastes and for other "hazardous" (i.e., hazardous, special, toxic, industrial, commercial, etc.) wastes. However, the association between hazardous wastes exposure and health effects has been discussed in several studies [8]. Obviously, a separate discussion should be held concerning the health and environmental impacts of illegal waste management practices (e.g., illegal waste burying in areas not designated as waste dump sites and illegal waste burning and the fires), which can also have an impact on the environment and health, with a number of documented cases $[9,10]$. In any case, the abovementioned associations can be considered as relevant only when defined in rigorously conducted epidemiology studies [8]. In this regard, a systematic review of the literature regarding the health effects of waste management [1] outlined that—given that a limited amount of evidence has been found for some associations and only a few studies have been selected for a quantitative evaluation of the health effects—-the overall evidence was generally inadequate to 
establish a specific relationship between a waste process and health effects. The same review outlined that most of the studies indicated weaknesses in their results, mainly due to experimental design issues. In fact, most of the available studies were characterized by limitations related to poor exposure assessment, aggregate level of analysis, and lack of information on relevant confounders [1]. Other major problems include the lack of scientific information for risk assessment and the need of more resources for the assessment of chemicals for which data are not available [8]. Similarly, Barba et al. concluded that the available evidence suffers from limitations mainly due to study design, lack of consideration of confounders and quality of the exposure data [11]. Thus, although many studies and reviews are available, the lack of adequate and accurate data on exposure levels represents one of the major issue in the evaluation of health effects arising from exposure to waste management processes $[10,12,13]$.

\section{Exposure Assessment in Studies on Health Impact of Waste Management}

Focusing on exposure assessment, it is worth noting that the "exposure" to chemical pollutants from waste management processes means coming into contact with chemical substances that can potentially cause adverse health effects, which are modulated by the toxicity of substances, the susceptibility of exposed individuals, and the extent and exposure pattern. The main pathways of exposure are (i) inhalation due to emissions from incinerators and landfills; (ii) consumption of contaminated water (i.e., water supplies contaminated with landfill leachate); and (iii) food chain (i.e., food enriched with persistent organic chemicals that may be released from incinerators) [12]. In this regard, human exposure to pollutants resulting from either incinerators or landfills can be very low, or even negligible, if proper operating procedures are followed and normal controls are maintained. Obviously, it is mandatory that waste management facilities are properly designed, operated, and monitored to ensure acceptable levels of emissions for airborne pollutants as well as corresponding levels of environmental and health risks (i.e., levels of pollutants in water and food should be controlled and regulated to reduce the likelihood of adverse impacts from these pathways) [14]. The health impact depends also on waste composition, disposal practices and consequent emissions, but a previous study provided a summary of the main known emissions and environmental impacts of waste management activities [12]. For example, the most common air pollutants associated with waste incineration processes are (i) inorganic major-pollutants-i.e., with emission in the order of $\mathrm{mg} / \mathrm{m}^{3}$ or $\mu \mathrm{g} / \mathrm{m}^{3}$ - such as particulate matter, heavy metals, $\mathrm{SO}_{2}$, $\mathrm{NO}_{x}, \mathrm{~N}_{2} \mathrm{O}, \mathrm{HCl}, \mathrm{HF}, \mathrm{CO}$ and $\mathrm{CO}_{2}$; and (ii) organic micro-pollutants-i.e., with emission in the order of $\mathrm{ng} / \mathrm{m}^{3}$ or below-such as dioxins, furans, polycyclic aromatic hydrocarbons (PAHs), volatile organic compounds (VOCs). Similarly, landfilling emissions could have an impact on air (e.g., emission of $\mathrm{CO}_{2}, \mathrm{CH}_{4}$ and VOCs). As already stated, both these processes also have an impact on groundwater or surface water quality (e.g., contaminated leachate from landfilling, fall-out of atmospheric pollutants from incineration) and on contamination of soils (e.g., heavy metals, synthetic organic compounds, fly ash, slags emitted from waste-disposal facilities) [12]. Further, it should be considered that, despite emissions from waste-disposal facilities having changed considerably over the last few decades (at least in more technologically advanced countries), in response to increasingly stringent limits on emissions set in legislative requirements, hazardous substances still continue to be released into the environment, contributing to the background levels of the surrounding areas [14]. Besides, exposure to substances released at waste management facilities can be acute (short-term exposure to high levels of potentially hazardous substances) and chronic, when it involves long-term exposure to low concentrations of these pollutants [12]. Thus, populations living near waste management facilities are therefore potentially exposed to a wide variety of pollutants-even at very low concentrations-directly associated with waste management processes, via inhalation of polluted air, ingestion of polluted food and water, or dermal contact with polluted soil [8,14]. Then, the exposure assessment process involves the determination of the magnitude, frequency and duration of current, past, and future exposure, as well as the identification of potential exposure pathways and 
exposed populations, including those particularly susceptible [14]; information on emitted pollutants potentially implying impacts on the environment and health and about common exposure patterns of the study population is therefore primarily necessary. It is well known that different approaches exist for exposure assessment: direct methods (personal monitoring of pollutants, biological monitoring) or indirect methods (environmental monitoring, models, questionnaire, diaries) are so-classified depending on both the fact that the selected sampling system involves/does not involve personal measurements and the variable they measure (i.e., the levels of exposure itself or factors that affect exposure). Other alternative approaches could be used to quantify exposure (for example, termed point-of-contact measurement, reconstruction of internal dose, and scenario evaluation). In any case, in order to evaluate the potential health impact on a population associated to waste management facilities, epidemiologists need to investigate the occurrence of clinical effects-which are typically characterized by a small incidence-in a population of adequate width (i.e., in the order of thousands of subjects) that may have been affected by emissions, which are likely to be exposed to levels slightly above environmental background concentrations, in large observational studies [12]. However, focusing again on the exposure assessment issue, although exposure to pollutants from another pattern may also have an impact on health, airborne exposure is often the pathway of greatest concern [14]. In any case, generally, data on direct human exposure are unfortunately very limited, and thus the exposure assessment process becomes even more complicated. As a consequence, most studies generally resorted only to surrogates such as residence information/distance from the source, with only few studies including data on potential exposure pathways (e.g., pollutant concentration in soil, modelled atmospheric exposure and dispersion of airborne pollutants) $[1,12,15]$. In this regard, the lack of accurate information on exposure levels represents undoubtedly the major issue in the evaluation of waste management-related health impacts [10]. More in general, previous studies outlined that the exposure assessment often represented the main uncertainty in epidemiological studies, mainly due to inadequate methods, which introduced misclassification of exposure with a consequent decrease in the likelihood of detecting significant exposure-effect associations $[1,12,13]$. Future studies in this field should require improvement in the characterization of individual exposures; in this regard, one of the most promising progresses in the exposure science is the development of miniaturized instruments for participatory and ubiquitous monitoring strategies for airborne pollutants [16]. Different studies have shown how measurement data characterized by high temporal and spatial resolution are essential for personal exposure assessments, in particular when considering heterogeneous and complex environments [16,17]. The use of these miniaturized devices and/or network of devices, once validated and in the presence of standardized monitoring procedures, could easily reduce the current biases (in terms of accuracy) of exposure assessment studies, at least for some major pollutants such as particulate matter, carbon monoxide and nitrogen oxides. Dynamic mapping of major air pollutants could allow for a deeper refinement of human exposure estimates for large populations and a better identification of areas of poor air quality [18]. As outlined in Deary et al., this approach has the major advantage of determining the personal exposure (for example, considering intra-daily variability or exposures in different microenvironments), thus providing a better estimation of health impacts that is not simply reliant on a generalized method for exposure derivation using exposure surrogates, fixed measurement stations or dispersion modelling [19]. However, despite the encouraging perspective of a more effective exposure characterization for some major pollutants, the monitoring of some micro-pollutants (e.g., dioxins, furans, polycyclic aromatic hydrocarbons, volatile organic compounds) typically related to emissions from waste management facilities is not so straightforward nowadays [19]. Nevertheless, the development of such approaches would be highly important since these could be applied in high-quality, low-cost, high-sensitivity exposure assessment studies and in spatially detailed monitoring networks. However, as stated before, most studies in the field generally try to overcome the lack of measured exposure data by using exposure surrogates. In some cases, the estimated differences in exposure of the study subjects are mainly or only related to differences in the proximity to the sources, with the possible introduction of large 
and not correctly assessed biases. Contrariwise, dispersion models have been demonstrated to be effective tools to improve exposure assessment and most advanced epidemiological studies assign exposure to individuals based on residential outdoor concentrations of air pollutants measured or estimated at the front-door $[20,21]$. This approach, however, is not devoid of errors: a recent study showed high potential for misclassification in the epidemiological studies that assign exposure-based concentrations estimated or measured at subjects' home addresses [22]. Furthermore, it should be remembered that inhalation exposure to airborne pollutants represents only one of the possible exposure patterns. Considering this, biological monitoring and the consequent study of specific biomarkers could allow an estimate of the amount of pollutants absorbed by each individual through different exposure patterns. Unfortunately, only a few studies are available in literature concerning the use of biomarkers to assess the effects of exposure of the general population to emissions from waste management facilities [12]. This is probably due to the fact that this approach is not always feasible in epidemiologic studies, especially those involving large population groups, since biological monitoring presents several challenges, such as the low concentrations of substances to be measured in complex biological matrices and the difficulty in interpreting results due to the many exposure sources [23]. Finally, the need of extensive and detailed exposure studies aimed to clarify the potential link between illegal waste-disposal practices and the health impact on the population was recently discussed [24]; in particular, the need of more detailed epidemiological studies was outlined, which, however, would transpose in a very demanding strategy, assisted by multidisciplinary exposure assessment studies, including (i) the accurate mapping and characterization of all the potentially contaminated sites (i.e., the waste management sites, including the surrounding superficial water, groundwaters and soils which may be subjected to contaminations); (ii) human biomonitoring programs; and (iii) deeply-investigated individual exposure assessment.

\section{Conclusions}

In summary, most of the existing studies concerning the evaluation of the health impacts of waste management facilities are afflicted by limitations, which are often related to poor exposure assessment. This issue poses specific challenges, due to the great variability of emitted pollutants, exposure patterns and of the potential associated health outcomes. Reflecting the current state-of-the-art, it is possible to conclude that despite some recent efforts, methodological gaps persist in currently used exposure assessment techniques, such as direct (personal monitoring of pollutants, biological monitoring) or indirect (environmental monitoring, models) methods, as well as alternative approaches and exposure surrogates. Since each of these approaches is based on different data and has strengths and limitations, it is advisable to use combined approaches to reinforce the reliability of the exposure assessment [14]. In particular, exposure assessment could be approached with a tiered approach, progressing from less refined, more conservative assessment methods, to more refined methods. In a first step evaluation, models based on generic scenarios and conservative assumptions can be used to perform a preliminary indirect exposure assessment; the advantage is that initial exposure estimates can be developed with a small amount of data, but with the possible limit of having a high level of uncertainty (due to the need to include assumptions and inferences given the limited data). Subsequently, if the preliminary estimated exposure is not considered to be negligible, a more detailed and accurate exposure assessment will be desirable. More accurate and specific evaluation of the exposure can be developed using representative exposure data of known quality; for this purpose, it is recognized that the use of reliable and relevant measured exposure (i.e., from personal/environmental and biological monitoring) is generally preferred over estimated exposure, given the uncertainties which may be associated to the use of certain models. It also should be stressed that while reliable field data are always preferable, proper measured data on exposure levels are often not available or difficult to obtain, thus the quality of such data and the relevance to the exposed population should be carefully considered. Thus, the use of more sophisticated and accurate models can certainly improve the exposure assessment procedures. Finally, the quantitative results of a robust and accurate 
exposure assessment should be combined with the results of health effects assessments (i.e., risk characterization phase) in order to evaluate whether or not there is any relationship of concern for the exposed populations [25]. In any case, the comprehensive characterization of human exposure to waste-management emissions will probably remain a challenge in the future: technical and scientific improvements (e.g., newly developed methods with adequate specificity, accuracy and sensitivity) and the definition of harmonized strategies (to ensure reliable and cost- and time-effective studies) for exposure assessment are certainly needed.

Acknowledgments: This communication summarizes and reports on previous studies by others, whose work is acknowledged in the text and references. This work has been set up in the framework of The European Union Chemical Biological Radiological and Nuclear Risk Mitigation Centres of Excellence Initiative (CBRN CoE) Project 35-Management of Hazardous Chemical and Biological Waste in the African Atlantic Facade Region, financed by the European Union Managed by The Commission's Directorate-General for International Cooperation and Development (DG DEVCO) under Contract No. IFS-2013-323494.

Author Contributions: The idea of this communication was defined by Andrea Spinazzè and Domenico Maria Cavallo. The manuscript draft was written by Andrea Spinazzè and was substantially revised by Francesca Borghi, Sabrina Rovelli and Domenico Maria Cavallo.

Conflicts of Interest: The authors declare no conflict of interest.

\section{References}

1. Porta, D.; Milani, S.; Lazzarino, A.I.; Perucci, C.A.; Forastiere, F. Systematic review of epidemiological studies on health effects associated with management of solid waste. Environ. Health 2009, 81, 60. [CrossRef] [PubMed]

2. Saunders, P. A systematic review of the evidence of an increased risk of adverse birth outcomes in populations living in the vicinity of landfill waste disposal sites. In Population Health and Waste Management: Scientific Data and Policy Options. Report of a WHO Workshop Rome, Italy, 29-30 March 2007; World Health Organization: Geneva, Switzerland, 2007.

3. Martuzzi, M.; Mitis, F.; Forastiere, F. Inequalities, inequities, environmental justice in waste management and health. Eur. J. Public Health 2010, 201, 21-26. [CrossRef] [PubMed]

4. Vrijheid, M. Health effects of residence near hazardous waste landfill sites: A review of epidemiologic literature. Environ. Health Perspect. 2000, 1081, 101-112. [CrossRef]

5. Rushton, L. Health hazards and waste management. Br. Med. Bull. 2003, 68, 183-197. [CrossRef] [PubMed]

6. Franchini, M.; Rial, M.; Buiatti, E.; Bianchi, F. Health effects of exposure to waste incinerator emissions: A review of epidemiological studies. Ann. Ist. Super Sanita. 2004, 40, 101-115. [PubMed]

7. Hu, S.W.; Shy, C.M. Health effects of waste incineration: A review of epidemiologic studies. J. Air Waste Manag. Assoc. 2001, 51, 1100-1109. [CrossRef] [PubMed]

8. De Rosa, C.T.; Fay, M.; Keith, L.S.; Mumtaz, M.M.; Pohl, H.R.; Hatcher, M.T.; Hicks, H.E.; Holler, J.; Ruiz, P.; Johnson, B.L. Hazardous wastes. In International Encyclopedia of Public Health; Heggenhougen, H.K., Ed.; Academic Press: Oxford, UK, 2008; pp. 107-121.

9. Comba, P.; Bianchi, F.; Fazzo, L.; Martina, L.; Menegozzo, M.; Minichilli, F.; Mitis, F.; Musmeci, L.; Pizzuti, R.; Santoro, M.; et al. Cancer mortality in an area of Campania (Italy) characterized by multiple toxic dumping sites. Ann. N. Y. Acad. Sci. 2006, 1076, 449-461. [CrossRef] [PubMed]

10. Triassi, M.; Alfano, R.; Illario, M.; Nardone, A.; Caporale, O.; Montuori, P. Environmental pollution from illegal waste disposal and health effects: A review on the "Triangle of Death". Int. J. Environ. Res. Public Health 2015, 12, 1216-1236. [CrossRef] [PubMed]

11. Barba, M.; Mazza, A.; Guerriero, C.; Di Maio, M.; Romeo, F.; Maranta, P.; Marino, I.R.; Paggi, M.G.; Giordano, A. Wasting lives: The effects of toxic waste exposure on health. The case of Campania, Southern Italy. Cancer Biol. Ther. 2011, 12, 106-111. [CrossRef] [PubMed]

12. Giusti, L. A review of waste management practices and their impact on human health. Waste Manag. 2009, 29, 2227-2239. [CrossRef] [PubMed]

13. Mattiello, A.; Chiodini, P.; Bianco, E.; Forgione, N.; Flammia, I.; Gallo, C.; Pizzuti, R.; Panico, S. Health effects associated with the disposal of solid waste in landfills and incinerators in populations living in surrounding areas: A systematic review. Int. J. Public Health 2013, 58, 725-735. [CrossRef] [PubMed] 
14. Reis, M.F. Solid Waste incinerators: Health impacts. In Encyclopedia of Environmental Health; Nriagu, J.O., Ed.; Elsevier: Burlington, MA, USA, 2011; pp. 162-217.

15. Candela, S.; Bonvicini, L.; Ranzi, A.; Baldacchini, F.; Broccoli, S.; Cordioli, M.; Carretta, E.; Luberto, F.; Angelini, P.; Evangelista, A.; et al. Exposure to emissions from municipal solid waste incinerators and miscarriages: A multisite study of the MONITER Project. Environ. Int. 2015, 78, 51-60. [CrossRef] [PubMed]

16. Carminati, M.; Ferrari, G.; Sampietro, M. Emerging miniaturized technologies for airborne particulate matter pervasive monitoring. Measurement 2017, 101, 250-256. [CrossRef]

17. Mead, M.I.; Popoola, O.A.M.; Stewart, G.B.; Landshoff, P.; Calleja, M.; Hayesb, M.; Baldovi, J.J.; McLeod, M.W.; Hodgson, T.F.; Dicks, J.; et al. The use of electrochemical sensors for monitoring urban air quality in low-cost, high-density networks. Atm. Environ. 2013, 70, 186-203. [CrossRef]

18. Moltchanov, S.; Levy, I.; Etzion, Y.; Lerner, U.; Broday, D.M.; Fishbain, B. On the feasibility of measuring urban air pollution by wireless distributed sensor networks. Sci. Total Environ. 2015, 502, 537-547. [CrossRef] [PubMed]

19. Deary, M.E.; Bainbridge, S.J.; Kerr, A.; McAllister, A.; Shrimpton, T. Practicalities of mapping $\mathrm{PM}_{10}$ and $\mathrm{PM}_{2.5}$ concentrations on city-wide scales using a portable particulate monitor. Air Qual. Atmos. Health 2016, 9, 923-930. [CrossRef] [PubMed]

20. De Hoogh, K.; Korek, M.; Vienneau, D.; Keuken, M.; Kukkonen, J.; Nieuwenhuijsen, M.J.; Chiara, B.; Beelen, R.; Bolignano, A.; Cesaroni, G.; et al. Comparing land use regression and dispersion modelling to assess residential exposure to ambient air pollution for epidemiological studies. Environ. Int. 2014, 73, 382-392. [CrossRef] [PubMed]

21. Beelen, R.; Raaschou-Nielsen, O.; Stafoggia, M.; Andersen, Z.J.; Weinmayr, G.; Hoffmann, B.; Wolf, K.; Samoli, E.; Fischer, P.; Nieuwenhuijsen, M.; et al. Effects of long-term exposure to air pollution on natural-cause mortality: An analysis of 22 European cohorts within the multicentre ESCAPE project. Lancet 2014, 383, 785-795. [CrossRef]

22. Zauli Sajani, S.; Trentini, A.; Rovelli, S.; Ricciardelli, I.; Marchesi, S.; Maccone, C.; Bacco, D.; Ferrari, S.; Scotto, F.; Zigola, C.; et al. Is particulate air pollution at the front door a good proxy of residential exposure? Environ. Pollut. 2016, 213, 347-358. [CrossRef] [PubMed]

23. Ranzi, A.; Fustinoni, S.; Erspamer, L.; Campo, L.; Gatti, M.G.; Bechtold, P.; Bonassi, S.; Trenti, T.; Goldoni, C.A.; Bertazzi, P.A.; et al. Biomonitoring of the general population living near a modern solid waste incinerator: A pilot study in Modena, Italy. Environ. Int. 2013, 61, 88-97. [CrossRef] [PubMed]

24. Bifulco, M. Comments on Triassi et al. Environmental Pollution from Illegal Waste Disposal and Health Effects: A Review on the "Triangle of Death". Int. J. Environ. Res. Public Health 2015, 12, 3358-3359. [CrossRef] [PubMed]

25. Van Engelen, J.G.M.; Hakkinen, P.J.; Money, C.; Rikken, M.G.J.; Vermeire, T.G. Human exposure assessment. In Risk Assessment of Chemicals, 2nd ed.; Springer: Dordrecht, The Netherlands, 2007; pp. 195-226. 